\title{
Global Impact of Peripheral Obstructive Arterial Disease in Portugal: An Eight Year Study
}

\author{
Impacto Global da Doença Arterial Obstrutiva Periférica \\ em Portugal: Estudo num Período de Oito Anos
}

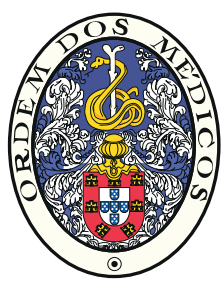

\author{
Mariana MOUTINHO ${ }^{1}$, Inês SIMÕES², Sónia RODRIGUES², Daisy ABREU², Emanuel SILVA', Paulo SOUSA ${ }^{2,3}$, \\ José Fernandes e FERNANDES1 \\ Acta Med Port 2019 May;32(5):348-354 - https://doi.org/10.20344/amp.10822
}

\section{ABSTRACT}

Introduction: Peripheral arterial disease has an important impact on morbidity/mortality. The objective of this study was to quantify the impact of this disease in Portugal during the last eight years, expressed by the volume of admissions, treatment strategies and associated morbidity and mortality.

Material and Methods: We collected data from the Diagnosis Related Group national database on primary diagnosis, procedures codes, demographic variables, a number of risk factors, and mortality of all cases admitted from 2009 to 2016 with a primary diagnosis of peripheral arterial disease coded according to the $9^{\text {th }}$ revision of the International Statistical Classification of Diseases and Related Health Problems (ICD-9).

Results: In this study, peripheral arterial disease led to 27684 hospitalisations, which corresponded to $26.7 \%$ of all admissions for vascular disease in this period. Approximately $49.9 \%$ of patients were admitted to the emergency department. The volume of procedures in patients with claudication decreased over the eight years, unlike patients with critical ischaemia, in which the number of procedures increased.

Discussion: Age and the presence of cardiovascular risk factors have been associated with the severity of disease, as observed in our series. Overall hospital mortality varied, being significantly higher in patients with more advanced severity of the disease.

Conclusion: Peripheral arterial disease represents an important burden in the overall volume of admissions in Portuguese public hospitals. A large number of patients was admitted in the context of emergency.

Keywords: Arterial Occlusive Diseases/epidemiology; Peripheral Vascular Diseases/epidemiology

\section{RESUMO}

Introdução: A doença arterial obstrutiva periférica tem um importante impacto a nível de morbi/mortalidade. O objetivo deste trabalho é quantificar o impacto desta doença em Portugal, ao longo dos últimos oito anos, expresso pelo volume de internamento, tratamento e pela morbi-mortalidade respetiva.

Material e Métodos: Foram analisados os registos de internamento no Serviço Nacional de Saúde entre 2009 e 2016 da base de dados dos grupos de diagnósticos homogéneos utilizando os códigos $9^{\text {th }}$ revision of the International Statistical Classification of Diseases and Related Health Problems (ICD-9) de diagnóstico e procedimentos. Verificámos o número de casos em cada ano por estadio de doença, dados demográficos, fatores de risco, tratamento e morbi-mortalidade.

Resultados: No período de estudo a doença arterial periférica conduziu a 27684 internamentos o que correspondeu a cerca de $26,7 \%$ do total de internamentos por patologia vascular neste período. Cerca de 49,9\% dos doentes foram admitidos em contexto de urgência. Os procedimentos em doentes claudicantes diminuíram ao longo dos oito anos ao contrário dos doentes com isquémia crítica em que os procedimentos aumentaram.

Discussão: A idade e a presença de fatores de risco cardiovasculares têm sido associadas à gravidade da doença, tal como na nossa série. A mortalidade hospitalar global varia, sendo mais significativa nos doentes com doença mais avançada.

Conclusão: A doença arterial periférica é uma patologia com importante representação no internamento dos hospitais do Serviço Nacional de Saúde. Há ainda um importante volume de doentes admitidos no contexto de urgência o que sugere eventual falta de reconhecimento/referenciação atempada por parte dos cuidados saúde primários, devendo mais esforços ser realizados no sentido de aumentar a interação entre os cuidados de saúde primários e os hospitais terciários.

Palavras-chave: Arteriopatias Oclusivas/epidemiologia; Doenças Vasculares Periféricas/epidemiologia

\section{INTRODUCTION}

The increase in life expectancy and aging of the population, combined with the lifestyle adopted by most populations, has changed the global epidemiology of atherosclerosis and arterial disease.

It has been estimated that about 202 million people live with peripheral arterial disease (PAD), meaning a very significant disease burden considering their direct and indirect contribution to global morbidity and mortality. ${ }^{1}$
In a study conducted in the United States of America (USA), based on data from the National Health and Nutrition Examination Survey between 1999 and 2000, the prevalence of PAD was about $4.3 \%$; this figure was higher in men, and increased dramatically with age $(0.9 \%$ in subjects under 50 years of age and $14.5 \%$ in individuals aged 70 years or over). ${ }^{2,3}$

In Portugal, and according to a study undertaken by

1. Departamento de Coração e Vasos. Serviço de Cirurgia Vascular. Hospital de Santa Maria. Centro Hospitalar Lisboa Norte. Lisboa. Portugal.

2. Departamento de Estratégias de Ação em Saúde. Escola Nacional de Saúde Pública. Universidade NOVA de Lisboa. Lisboa. Portugal.

3. Centro de Investigação em Saúde Pública. Escola Nacional de Saúde Pública. Universidade NOVA de Lisboa. Lisboa. Portugal.

$\triangle$ Autor correspondente: Mariana Moutinho. mariana6sasm@gmail.com

Recebido: 21 de maio de 2018 - Aceite: 06 de dezembro de 2018 | Copyright @ Ordem dos Médicos 2019 
the Portuguese Society of Angiology and Vascular Surgery (SPACV) in 2008, which included 5731 individuals in Mainland Portugal (average age 67 years), 132 in Madeira and 122 in Azores, the prevalence of PAD in the Continent was $5.9 \%$, being approximately 2 times higher in males $(8.4 \%$ vs $4.1 \%)^{4}$

It is expected that the prevalence of PAD increases with the aging of the population, the persistence of smoking ${ }^{5}$ and the increase of risk factors such as diabetes mellitus, obesity and hypertension. ${ }^{3}$

In asymptomatic patients, $26 \%$ develop critical limb ischaemia one year after diagnosis. In patients with critical ischaemia, with no revascularisation standard, approximately $40 \%$ lose lower limb integrity within six months and more than $20 \%$ die. $^{6}$

Regarding the natural history, in a recent meta-analysis, ${ }^{7}$ most patients with intermittent claudication presented an increased 5-year cumulative cardiovascular-related morbidity, with a level of $13 \%$ vs $5 \%$ in the reference population. Regarding the limb risk, $21 \%$ of patients progress to chronic limb-threatening ischaemia at 5 years, of whom $4 \%-27 \%$ undergo amputations. ${ }^{6}$

Some studies also suggest that PAD, even in asymptomatic patients, is associated with a level of morbidity and mortality that is comparable to coronary and cerebrovascular disease and possibly at a higher cost. ${ }^{8}$ Patients with an ankle brachial index $(\mathrm{ABI})<0.9$, regardless of whether or not they present with symptoms, have a level of morbidity and mortality that is higher than individuals of the same age group with normal ABI.9,10,11 According to Fowkes et al, individuals with a diagnosis of PAD with or without symptoms of lower limb ischaemia have an approximately three times higher risk of mortality and major cardiovascular events [acute myocardial infarction (AMI) and stroke] compared to individuals without PAD. ${ }^{9}$ Between 45 and 202 million people with PAD die of coronary or cerebrovascular disease within a 10 -year period, with the risk of amputation ranging from $1 \%-3 \%$ in five years and may reach $90 \%$ in patients with critical ischaemia. ${ }^{1}$

The economic impact of this condition has been evaluated in several countries, particularly in the USA, and analyses of data from the Reduction of Atherothrombosis for Continued Health Registry assessed the total hospitalisation costs related to arterial pathology at around 21 billion dollars, with most of the costs being associated with revascularisation procedures. ${ }^{12}$

The purpose of this study was to characterise the impact of peripheral arterial disease on the National Health Service (NHS) in Portugal over the last eight years, quantifying hospitalisation, treatment, morbidity and mortality.

\section{MATERIAL AND METHODS}

This investigation is part of a project entitled "Vascular Surgery in Portugal: Knowing to Improve", a partnership between the National School of Public Health, NOVA University, and the Faculty of Medicine of the University of Lisbon, which was supported by Fundação Calouste Gulbenkian.
Data were obtained from the Diagnosis Related Group (DRG) national database which contains data from all admissions to Portuguese public hospitals (mainland Portugal). We collected data on primary diagnosis, procedures codes, demographic variables (such as sex and age), a number of risk factors, and mortality rate. All cases admitted between 2009 and 2016 with a primary diagnosis of PAD coded in $9^{\text {th }}$ revision of the International Statistical Classification of Diseases and Related Health Problems (ICD-9) as indicated in Table 1 (diagnosis) were analysed.

The number of cases in each year was recorded along with demographic data (sex, age), disease stage, risk factors, treatment, hospital morbidity and mortality, as well as the evolution of hospitalisation levels for PAD throughout these eight years. We compared the type of admission, the number of hospitalised patients, the duration of hospital admission, the mortality rate and the percentage of patients discharged from hospital according to the various stages of the disease.

After identifying the population with PAD involving the lower limbs, the diagnostic codes were cross-referenced with the codes of the most commonly performed procedures in this condition, with the aim of finding a pattern or trend in the treatment of these patients during the aforementioned time period.

\section{Statistical analysis}

The comparison between groups for continuous variables was performed using analysis of variance (ANOVA), with an adjustment for multiple comparisons through the Bonferroni test. T-student test was applied if the categorical variable presented only two categories. Trend analyses were performed using simple linear regression. Comparisons between categorical variables were made using the chi-square test. The analyses were performed using SPSS version 22 and considering $p<0.05$ as the threshold for significance.

\section{RESULTS}

Although the number of hospitalisations due to vascular disease (obstructive carotid disease, deep venous thrombosis, chronic venous insufficiency, acute lower limb ischemia, peripheral arterial disease, abdominal and peripheral artery aneurysms, and vascular trauma) decreased over a period of six years (19 267 in 2009 to 14381 in 2014), hospitalisation levels for PAD remained relatively stable, with a tendency to increase from 4102 in 2009 to 4428 in 2015, with a slight decrease in 2016 to 3893.

During the period of our study, the diagnosis of PAD led to 27684 hospitalisations, which corresponded to about $0.6 \%$ of all admissions in adults and $26.7 \%$ of all hospitalisations due to vascular disease (obstructive carotid disease, deep venous thrombosis, chronic venous insufficiency, acute lower limb ischemia, peripheral arterial disease, abdominal and peripheral artery aneurysms, and vascular trauma). About 26825 hospitalisations were the result of atherosclerotic disease of the lower limbs (corresponding 
Table 1 - ICD-9 codes used in this paper

\begin{tabular}{|c|c|}
\hline Diagnosis/Procedures & Code \\
\hline \multicolumn{2}{|l|}{ Diagnosis } \\
\hline Atherosclerosis of the aorta & 440.0 \\
\hline Atherosclerosis of the native extremities & 440.2 \\
\hline Intermittent claudication & 440.21 \\
\hline Resting pain & 440.22 \\
\hline Ulcer & 440.23 \\
\hline Gangrene & 440.24 \\
\hline Chronic total occlusion of the arteries of the extremities & 440.4 \\
\hline Atherosclerosis of extremities bypass & 440.3 \\
\hline \multicolumn{2}{|l|}{ Procedures } \\
\hline \multicolumn{2}{|l|}{ Open Surgery } \\
\hline Aorto-iliac-femoral bypass & 39.25 \\
\hline Other peripheral vascular bypass & 39.29 \\
\hline Endarterectomy of the lower limbs & 38.18 \\
\hline Vessel repair with autologous patch & 39.56 \\
\hline Vessel repair with synthetic patch & 39.57 \\
\hline Vessel repair with non-specific patch & 39.58 \\
\hline \multicolumn{2}{|l|}{ Endovascular Procedure } \\
\hline Insertion of stent in peripheral vessel & 39.90 \\
\hline Non-coronary vessel angioplasty & 39.50 \\
\hline Insertion of stent with drug in peripheral vessel & 00.55 \\
\hline \multicolumn{2}{|l|}{ Review of lower limb vascular surgery } \\
\hline Control haemorrhage after vascular surgery & 39.41 \\
\hline Another review of vascular procedure & 39.49 \\
\hline
\end{tabular}

to $96.8 \%$ of the PAD) and of these, 238 corresponded to hospitalisations due to a recurrence of disease (i.e. patients previously subjected to procedures listed in Table 1 for peripheral arterial disease.).

Patients were grouped into five age groups: 18 to 24 years old, 25 to 44,45 to 64,65 to 84 , and older than 85 years old; $42.3 \%$ were aged between 65 and 84 years and more than half of the patients were male $(69.5 \%)$.

The most frequent comorbidities were arterial hypertension (HT) (13 228) and diabetes mellitus (DM) (9902) followed by dyslipidaemia (6302) and ischaemic heart disease (4360).

Regarding the type of admission, approximately $49.9 \%$ of patients hospitalised for PAD involving the lower limbs were admitted to hospital after presenting to an emergency department.

Patients with PAD were classified according to the ICD 9 classification by categories according to the following symptoms: claudication, rest pain, ischaemic leg ulceration and gangrene. In general, there appears to be a trend reflected by the reduction in hospitalisations at earlier stages (i.e. less severe, especially patients with claudication), as opposed to patients with more advanced stages, such as rest pain, leg ulcer and gangrene (Fig. 1).

For patients with claudication, the number of hospitalisations decreased from 811 to 363 between 2009 and 2016; this decrease was significant $(p=0.01)$.

The number of patients hospitalised for rest pain and leg ulcer increased from 505 to $595(p=0.015)$ and from 619 to $880(p<0.001)$, respectively, from 2009 to 2016 . The number of patients hospitalised for gangrene totalled 1824 in 2009 and reached a peak of 2206 cases in 2010. From 2010 to 2016, this number decreased slightly to around 2055, but was not statistically significant (Fig. 1).

Patients with intermittent claudication belonged to younger groups, with $51.2 \%$ being aged 45 - 64 years; on the contrary, in the groups with critical ischaemia, the predominant age group was older, with the majority being aged between 65 and 84 years. There is an increasing proportion of patients over 85 years of age as the disease stage progresses $(9.1 \%, 14.4 \%$ and $23.9 \%$ in patients with rest pain, leg ulcer and gangrene, respectively). Also, the period of hospitalisation and hospital mortality varied in a direct ratio with severity of the disease, with the number of days of hospitalisation being $5.43,9.2,16.4$ and 17.4 and mortality of $0.8 \%, 3.0 \%, 5.6 \%$ and $13.5 \%$, respectively, in patients with claudication, rest pain, ulcer and gangrene; the difference was statistically significant $(p<0.001)$. On the contrary, the percentage of patients who were discharged home decreased according to the severity of the disease: $95.8,89.5$, 86.3 and 78.3 in patients with claudication, rest pain, ulcer or gangrene, respectively (Table 2). Despite this trend, the 
overall mortality by PAD did not change over the eight-year period (Fig. 2).

Also, patients with more advanced disease (rest pain and/or ulceration and gangrene) had higher rates of admission in the emergency department compared to those with claudication: $85 \%$ vs $15 \%$ (Table 2 ).

Diagnostic codes were cross-referenced with the codes of the most commonly performed treatment procedures.
In the patients hospitalised for PAD involving the lower limbs (code 440.2), 12166 procedures were performed: 5925 $(48.7 \%)$ were open/conventional surgery, 5895 (48.5\%) were endovascular procedures and $346(2.8 \%)$ were revisions of previous surgeries. Regarding open surgery, the number of procedures remained relatively constant over the eight year period, with an average of 800 procedures per year; there was a statistically significant tendency for the

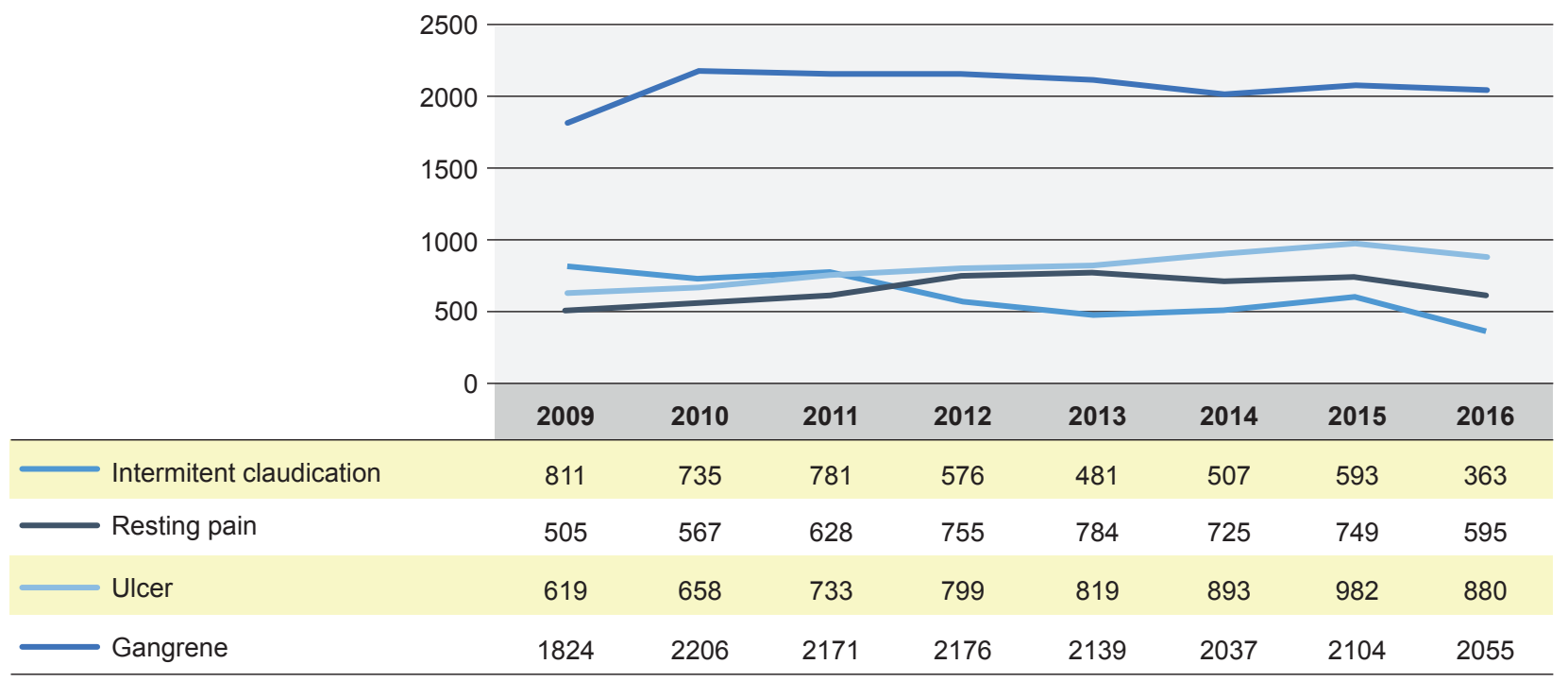

Figure 1 - Total number of patients hospitalised for PAD according to stage of disease between 2009 and 2016

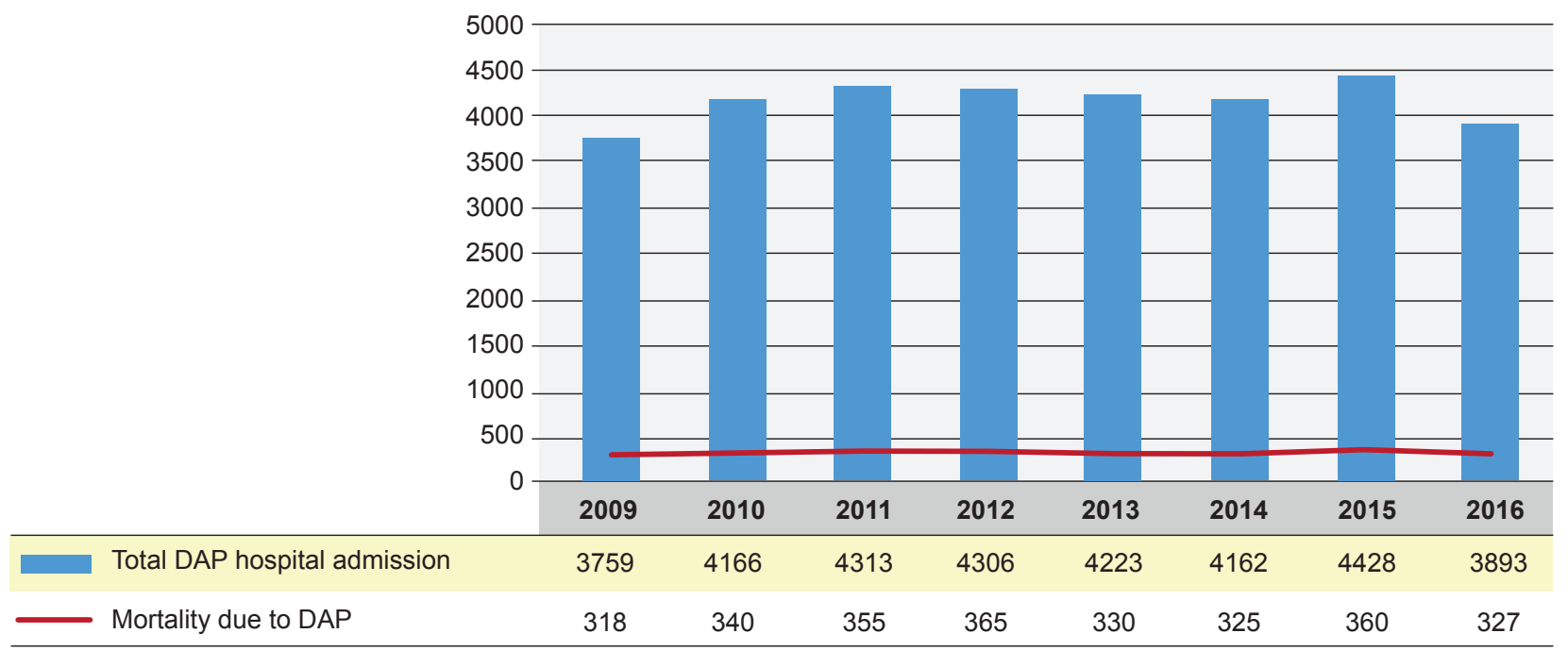

Figure 2 - DAP hospital admission (blue column) and mortality (red line) per year from 2009 to 2016

Table 2 - Predominant age group, duration of hospitalisation, mortality, home discharge and type of admission due to stage of disease

\begin{tabular}{|c|c|c|c|c|c|}
\hline Stages & Claudication & Rest pain & Ulcer & Gangrene & $p$ \\
\hline Age Group Predominant & $45-64$ & $65-84$ & $65-84$ & $65-84$ & \\
\hline $\begin{array}{l}\text { Type of Urgent Admission } \\
(\%)\end{array}$ & $\begin{array}{c}4847 \\
(15 \%)\end{array}$ & $\begin{array}{l}5308 \\
(16 \%)\end{array}$ & $\begin{array}{l}6383 \\
(19 \%)\end{array}$ & $\begin{array}{l}16712 \\
(50 \%)\end{array}$ & $<0.001$ \\
\hline $\begin{array}{l}\text { Days of hospitalization } \\
\text { (mean) }\end{array}$ & 5.43 & 9.2 & 16.4 & 17.4 & $<0.001$ \\
\hline $\begin{array}{l}\text { Mortality } \\
(\%)\end{array}$ & $\begin{array}{c}39 \\
(0.8 \%)\end{array}$ & $\begin{array}{c}158 \\
(3.0 \%)\end{array}$ & $\begin{array}{c}359 \\
(5.6 \%)\end{array}$ & $\begin{array}{c}2255 \\
(13.5 \%)\end{array}$ & $<0.001$ \\
\hline $\begin{array}{l}\text { Home Discharge } \\
(\%)\end{array}$ & $\begin{array}{c}4644 \\
(95.8 \%)\end{array}$ & $\begin{array}{c}4731 \\
(89.5 \%)\end{array}$ & $\begin{array}{c}5456 \\
(86.3 \%)\end{array}$ & $\begin{array}{c}12977 \\
(78.3 \%)\end{array}$ & $<0.001$ \\
\hline
\end{tabular}




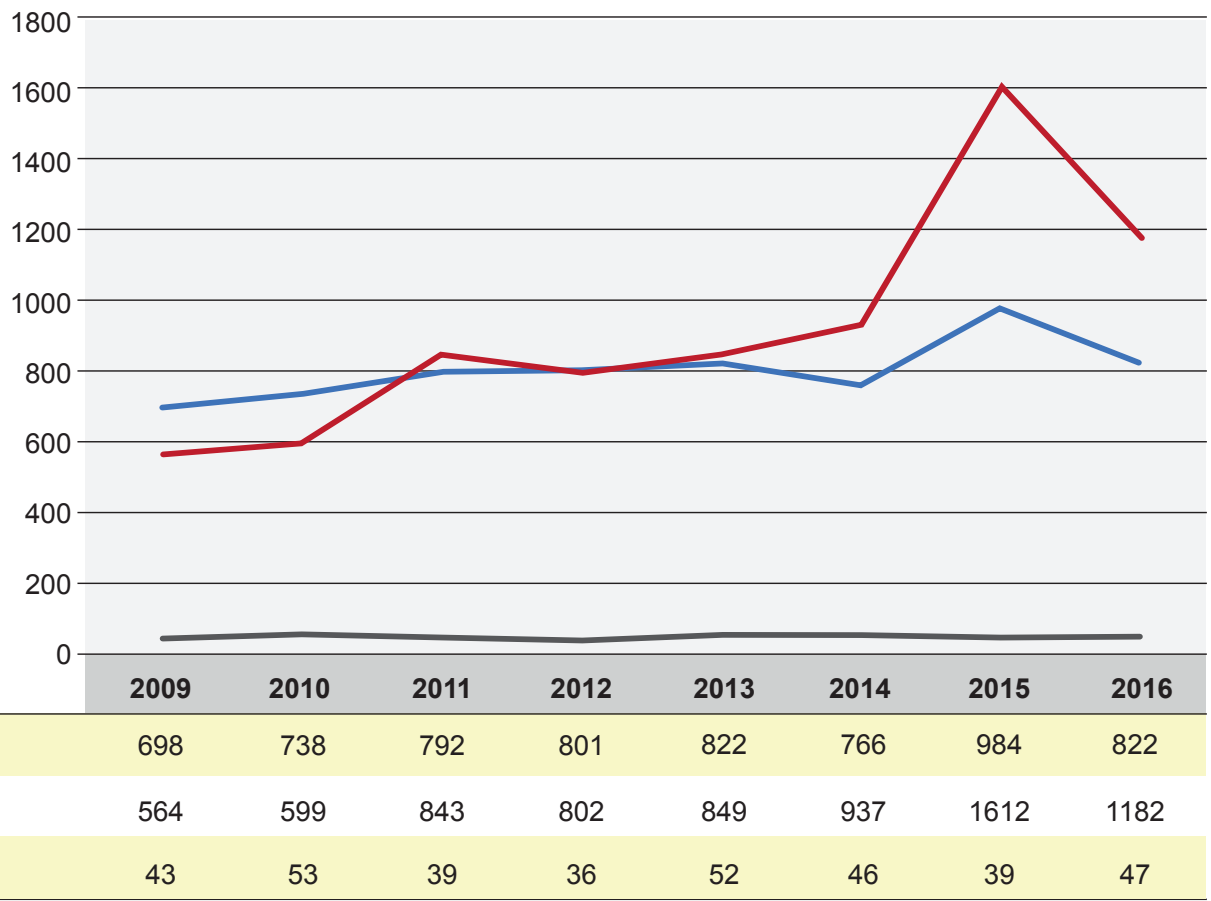

Figure 3 - Number of procedures performed during these eight years (open surgery: blue line; endovascular procedures: red line; reinterventions: grey line)

number of procedures to decrease from 822 to 766 in the period from 2013 and 2016. This reality is also true for hospitalisations in patients with a recurrence of disease, with values remaining stable throughout the studied period (average of 44 procedures per year). In contrast, endovascular treatment increased from 900 to 1609 from 2013 to 2015, with a rapid decrease in 2016 (Fig. 3).

The percentage of procedures performed in patients with claudication was $23 \%$, was $23.7 \%$ in hospitalised patients with rest pain, $21.2 \%$ in patients with leg ulcers and $32 \%$ in patients with gangrene. The difference between interventions performed in patients with claudication versus more advanced stages (resting pain + active ulcer + gangrene) was highly significant $(p<0.001)$ regardless of the type of treatment (open versus endovascular surgery).

In general, the number of procedures in patients with claudication decreased over the eight year period (from 455 to 323 in 2009 and 2016, respectively), unlike patients with critical ischaemia, in which the number of procedures increased in the eight year period [either openly (from 487 to 633 in 2009 and 2016), and patients undergoing endovascular procedures (from 326 to 735 in 2009 and 2016, respectively)].

Patients subjected to endovascular procedures had reduced lengths of stay in hospitals as well as reduced in-hospital mortality, as shown in Table 3; this difference was statistically significant (the $p$-values obtained are unadjusted).

\section{DISCUSSION}

PAD is a common manifestation of systemic atherosclerotic disease and, when present, it is a valuable indicator of severity, the involvement of other areas such as the cerebrovascular and coronary regions and also a marker of higher morbidity and mortality. PAD is also associated with a 5-fold increased short-term risk of AMI or stroke, and a 3 -fold increase in the risk of death when compared to individuals in the same age range without PAD., 2,13

Age and the presence of cardiovascular risk factors have been associated with the severity of disease and the same trend was also observed in our series, where more than $40 \%$ of patients were between 65 and 84 years and most had hypertension, diabetes mellitus and/or dyslipidaemia. ${ }^{14}$ Moreover, in our sample, more advanced clinical stages of PAD were present in older age groups, and frequently associated with more advanced systemic atherosclerotic disease, increased severity of their clinical manifestations and higher surgical risk, thus representing a greater burden of disease for hospital admissions within the NHS. According to Abu Dabrh et al, in a meta-analysis, there is a high rate of mortality and limb loss associated with critical limb ischemia (almost one in five patients during a median follow-up of one year) with wounds or ulcers more likely to worsen..$^{15}$

Health promotion, with the modification of risk factors and adequate lifestyle, as well as personal and social habits, are particularly important for the prevention of PAD in

Table 3 - Comparing open procedure with endovascular procedure considering number of days of hospitalisation and mortality

\begin{tabular}{lcccc} 
& Open Surgery & Endovascular Procedure & $\boldsymbol{p}$ & Both \\
\hline Days of hospitalisation & 20.07 & 12.95 & $<0.001$ & 21.43 \\
Mortality (\%) & 5.6 & 3.02 & $<0.001$ & 8.62 \\
\hline
\end{tabular}


order to reduce the burden of disease and its effect upon the use of resources within the NHS. Implementation and adherence to programs promoting healthy lifestyles, such as a balanced diet, smoking cessation and regular exercise, will be necessary to change the present reality of PAD in the Portuguese health service. The introduction of supervised exercise programs, as suggested by Mazari et al, ${ }^{16}$ where comparisons were performed in patients with claudication between those treated with endovascular revascularisation versus a conservative approach (supervised exercise protocol) was conducted. Reduction in the cost per quality-adjusted life year (QALY) gain was lower: $€ 6167$ for exercise versus $€ 11777$ for endovascular treatment, confirming supervised exercise as a cost-effective approach in the initial management of these patients. ${ }^{16,17,18}$

Annual hospital mortality rate for patients with asymptomatic PAD varies from $5 \%$ to $7 \%$, with this value being higher than the mortality due to coronary disease or stroke. ${ }^{19}$ The five-year mortality rate of patients with critical ischaemia ranged from $10 \%$ to $15 \%$ ( $75 \%$ were of cardiovascular origin), with the remaining $20 \%$ developing a non-fatal cardiovascular event. ${ }^{20}$ In our series, overall hospital mortality also varied, between $6 \%$ and $8 \%$, being significantly higher in patients with more advanced severity of the disease.

Several studies suggest that PAD is still an under-diagnosed and under-treated disease because it is often asymptomatic. In a study conducted in Canada by Morge et al, important gaps in knowledge and public awareness in the general population concerning PAD were identified in elder individuals with lower education levels. ${ }^{21}$

Another relevant issue in our series was the fact that $69 \%$ of the patients with gangrene (a more advanced stage of the disease) were admitted in an emergency setting, suggesting either late referral of these patients for observation and treatment in specialised vascular services or difficulty accessing those services. This represents an important issue and confirms a perception from our data of inadequate responses to the patients' need for adequate and timely recognition of the disease leading to the late treatment of patients with PAD.

Decisions concerning conventional open or endovascular revascularisation procedures for PAD treatment were beyond the scope of the present study. However, our data confirmed an increase in endovascular procedures over the eight year period and a reduction in the in-hospital mortality when compared with open conventional revascularisation. Despite this increase in endovascular treatment, the rates of open surgery and endovascular surgery were similar during the study period (48.7\% open surgery vs $48.5 \%$ endovascular treatment). The number of hospitalisations for recurrent arterial disease has tended to increase in the last year, although not significantly. This may be due to the increased use of endovascular techniques which have been associated with a greater number of re-interventions compared to open surgery.
In fact, our data confirm that PAD represents an important burden on public health care resources and associated evidence from other studies confirms the high prevalence of diabetes in the Portuguese population, ${ }^{22}$ it is therefore reasonable to expect that $\mathrm{PAD}$ will continue to represent a major burden upon public health resources in the future. Despite the limitations of our study, which is based on administrative data and not on clinical records, thus reducing the possibility of a more rigorous evaluation of the impact of smoking and other risk factors, separate analyses of the adequacy of each intervention for each individual case and a lack of information on long-term outcomes, our study provides information on the impact of PAD in hospital admissions in Portuguese public hospitals, on the evolution of treatment strategies within an eight year period and its impact on in-hospital mortality and duration of hospitalisation. The economic and clinical burden of cardiovascular disease in general and PAD in particular could not be assessed in our study; however, according to the published literature, they will present a major public health problem and a huge challenge for health systems in the near future. Greater and better clinic-based computer records should be implemented in order to obtain adequate information and to provide a more complete and thorough evaluation of the true impact of the disease in our country, the adequacy of the treatment strategies and its mid- and long-term efficacy. Therefore additional efforts are needed to increase communication between Primary Health Care Units and Hospitals.

\section{CONCLUSION}

Aging of the population and the increased prevalence of some risk factors suggest a continued high prevalence of PAD and an increased need for resources to provide timely and effective treatment for these patients. It was clear from our data that efforts should be made to improve the prevention of PAD and risk factor modification, as well as to promote the early referral of these patients to specialised treatment. Further efforts should be made to educate the population to increase the awareness of PAD and improve early diagnosis, as well as prompt referral to treatment in specialised vascular facilities, as major requirements to reduce the relevant clinical and economic impact on hospitalisation in NHS hospitals in Portugal.

\section{PROTECTION OF HUMANS AND ANIMALS}

The authors declare that the procedures were followed according to the regulations established by the Clinical Research and Ethics Committee and to the Helsinki Declaration of the World Medical Association.

\section{DATA CONFIDENTIALITY}

The authors declare having followed the protocols in use at their working center regarding patients' data publication. 


\section{CONFLICTS OF INTEREST}

All authors report no conflict of interest.

\section{REFERENCES}

1. Fowkes FG, Rudan D, Rudan I, Aboyans V, Denenberg JO, McDermott $\mathrm{MM}$, et al: Comparison of global estimates of prevalence and risk factors for peripheral artery disease in 2000 and 2010: a systematic review and analysis. Lancet. 2013;382:1329-40.

2. Selvin E, Erlinger TP. Prevalence of and risk factors for peripheral arterial disease in the United States: results from the National Health and Nutrition Examination Survey, 1999-2000. Circulation. 2004;110:738-43.

3. Society for Vascular Surgery Lower Extremity Guidelines Writing Group, Conte MS, Pomposelli FB, Clair DG, Geraghty PJ, McKinsey JF, et al. Society for Vascular Surgery practice guidelines for atherosclerotic occlusive disease of the lower extremities: management of asymptomatic disease and claudication. J Vasc Surg. 2015;61:2S-41.

4. Menezes JF, Carvalho C, Barbosa J, Mansilha A. Estudo da prevalência da doença arterial periférica em Portugal. Angiol Cir Vasc. 2009;5:2:5968.

5. Morris PB, Ference BA, Jahangir E, Feldman DN, Ryan JJ, Bahrami H, et al. Cardiovascular effects of exposure to cigarette smoke and electronic cigarettes: clinical perspectives from the Prevention of Cardiovascular Disease Section Leadership Council and Early Career Councils of the American College of Cardiology. J Am Coll Cardiol. 2015;66:1378-91.

6. Norgren L, Hiatt WR, Dormandy JA, Nehler MR, Harris KA, Fowkes FG, et al. Inter-Society Consensus for the Management of Peripheral Arterial Disease (TASC II). J Vasc Surg. 2007;45:S5-67.

7. Sigvant $\mathrm{BL}$, Wahlberg $\mathrm{E}$ : The risk of disease progression in peripheral arterial disease is higher than expected: a meta- analysis of mortality and disease progression in peripheral arterial disease. Eur $\mathrm{J}$ Vasc. 2016;51:395-403.

8. Piepoli MF, Hoes AW, Agewall S, Albus C, Brotons C, Catapano AL, et al: Piepoli MF, Hoes AW, Agewall S, Albus C, Brotons C, Catapano AL, et al: 2016 European guidelines on cardiovascular disease prevention in clinical practice. The Sixth Joint Task Force of the European Society of Cardiology and Other Societies on Cardiovascular Disease Prevention in Clinical Practice (constituted by representatives of 10 societies and by invited experts) developed with the special contribution of the European Association for Cardiovascular Prevention \& Rehabilitation (EACPR). Eur Heart J. 2016;37:2315-81.

9. Fowkes FG, Aboyans V, Fowkes FJ, Mcdermott MM, Sampson UK, Criqui $\mathrm{MH}$. Peripheral artery disease: epidemiology and global perspectives. Nat Rev Cardiol. 2017;14:156-70

10. Xu D, Zou L, Xing Y, Hou L, Wei Y, Zhang J, et al: Diagnostic value of

\section{FUNDING SOURCES}

Subsidies or grants that contributed to the work: Fundação Calouste Gulbenkian.

ankle-brachial index in peripheral arterial disease: a meta-analysis. Can J Cardiol. 2013;29:492-8

11. Tehan PE, Santos $D$, Chuter VH. A systematic review of the sensitivity and specificity of the toe-brachial index for detecting peripheral artery disease. Vasc Med. 2016;21:382-9.

12. Mahoney EM, Wang K, Keo HH, Duval S, Smolderen KG, Cohen DJ, et al. Vascular hospitalization rates and costs in patients with peripheral artery disease in the United States. Circ Cardiovasc Qual Outcomes. 2010;3:642-51.

13. Blinc A, Kozak M, Sabovic M, Bozic Mijovski M, Stegnar M, Poredos P, et al: Survival and event-free survival of patients with peripheral arterial disease undergoing prevention of cardiovascular disease. Int Angiol. 2017;36:216-27.

14. Criqui $\mathrm{MH}$, Aboyans V. Epidemiology of peripheral artery disease. Circ Res. 2015;116:1509-26.

15. Abu Dabrh AM, Steffen MW, Undavalli C, Asi N, Wang Z, Elamin MB, et al: The natural history of untreated severe or critical limb ischemia. J Vasc Surg. 2015;62:1642-51.

16. Mazari FA, Khan JA, Carradice D, Samuel N, Gohil R, McCollum PT, et al: Economic analysis of a randomized trial of percutaneous angioplasty, supervised exercise or combined treatment for intermittent claudication due to femoropopliteal arterial disease. Br J Surg. 2013;100:1172-9.

17. Gommans LN, Fokkenrood HJ, Van Dalen HC, Scheltinga MR, Teijink JA, Peters RJ. Safety of supervised exercise therapy in patients with intermittent claudication. J Vasc Surg. 2015;61:512-8.

18. Bermingham SL, Sparrow K, Mullis R, Fox M, Shearman C, Bradbury A, et al. The cost-effectiveness of supervised exercise for the treatment of intermittent claudication. Eur J Vasc Endovasc Surg. 2013;46:707-14.

19. Marrett E, Dibonaventura M, Zhang Q. Burden of peripheral arterial disease in Europe and the United States: a patient survey. Health Qual Life Outcomes. 2013;11:175.

20. Naschitz JE, Ambrosio DA, Chang JB. Intermittent claudication: predictors and outcome. Angiology. 1988;39:16-22.

21. Lovell M, Harris K, Forbes T, Twillman G, Abramson B, Criqui MH, et al. Peripheral arterial disease: lack of awareness in Canada. Can J Cardiol. 2009;25:39-45

22. Sociedade Portuguesa de Diabetologia. Diabetes: Factos e Números O Ano de 2015 - Relatório Anual do Observatório Nacional da Diabetes: Lisboa: SPD; 2016. 